\title{
ASPECTOS PSICOLÓGICOS EN PELÍCULAS SOBRE PANDEMIAS. CUANDO “NO SE PUEDE VER (EN) LA PANDEMIA”. A CIEGAS (2008), A CIEGAS (2018)
}

\section{Psychological Aspects in Movies about Pandemics. When "You Can't See (in) the Pandemic". Blindness, (2008), Bird Box (2018).}

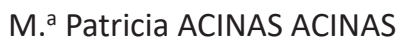 \\ Sociedad Española de Psicología Aplicada a Desastres, Urgencias y Emergencias (SEPADEM) (España). \\ Correo electrónico: acinas.patricia@gmail.com
}

Fecha de recepción: 16 de septiembre de 2020

Fecha de aceptación: 24 de septiembre de 2020

Fecha de publicación: 29 de enero de 2021

\section{Resumen}

Las situaciones en las que se pierde un sentido, como la vista, o debemos anularlo porque nuestra vida puede estar en juego, suponen una carga de estrés importante. Si además esto va aparejado con un contagio inexplicable y una transmisión de la patología sin causa aparente, y sin razón conocida, añade más malestar psicológico al malestar físico. El sentido de la vista es uno de los primordiales en la vida que llevamos en este siglo XXI. Las películas elegidas en este artículo ( $A$ ciegas, 2008 y A ciegas 2018), nos permiten reflexionar sobre estas cuestiones, en sentido literal y figurado.

Palabras clave: ceguera; esperanza; reacciones psicológicas; suicidio; daño.

\section{Abstract}

Situations in which a sense is lost, such as sight, or when we must cancel it, because our lives may be at stake, pose a significant stress load. If this is also coupled with an inexplicable contagion and a transmission of the pathology without apparent cause, and for no known reason, it adds more psychological discomfort to the physical discomfort. The sense of sight is one of the most 


\section{ASPECTOS PSICOLÓGICOS EN PELÍCULAS SOBRE PANDEMIAS. CUANDO “NO SE PUEDE VER (EN) LA PANDEMIA". A CIEGAS (2008), A CIEGAS (2018) \\ M. ${ }^{\text {a }}$ PATRICIA ACINAS ACINAS}

important in the life we lead in this 21st century. The films chosen in this article (Blindness, 2008 and Bird Box 2018), allow us to reflect on these issues, literally and figuratively.

Keywords: Blindness; hope; psychological reactions; suicide; harm.

Cuando ya no somos capaces de cambiar una situación, nos encontramos con el desafío de cambiarnos a nosotros mismos.

(Victor Frankl)

\section{INTRODUCCIÓN}

Desde la Psicología de emergencias ${ }^{1,2}$ conocemos que existen diversas manifestaciones psicológicas que aparecen ante una situación de emergencia o catástrofe. Los aspectos físicos, no los podemos separar de los aspectos psicológicos. Cuando se afecta la salud física, también hay manifestaciones psicológicas de diversa envergadura, intensidad y duración, que interaccionan de manera clara, produciendo en muchos casos malestar psicológico añadido.

En momentos de pandemia, emergencia continuada, algunas manifestaciones emocionales se muestran aún con mayor intensidad y de manera extensa en el tiempo. Asi aparecen emociones y sentimientos como incertidumbre, miedo a contagio, a ser contagiado, a ser vector de transmisión, disgusto, pena por el daño producido o recibido en sí mismo o en otros....

En este artículo vamos a hacer un análisis de algunos aspectos relacionados con pandemia pero también con aspectos psicoemocionales a través de dos películas que comparten algunos aspectos, entre ellos, el título en español A CIEGAS (Fernando Meirelles, 2008 y Susanne Bier, 2018)

\section{A Ciegas (2008). CuAndo descubrimos que LA VISTA ES IMPORTANTE}

\section{Ficha técnica}

Título: A ciegas.

Titulo original: Blindness.

Otros títulos: Ceguera (Latinoamérica).
País: Canadá. Brasil. Japón.

Año: 2008.

Director: Fernando Meirelles.

Música: Marco Antônio Guimarães.

Fotografía: César Charlone.

Montaje: Daniel Rezende.

Guion: Don McKellar basado en la novela homónima de José Saramago.

Intérpretes: Julianne Moore (esposa del médico), Mark Ruffalo (médico), Gael García Bernal (jefe de la sala 3), Danny Glover (viejo con una venda negra cubriéndole un ojo), Sandra Oh (Ministra de Salud), Yusuke Iseya (Primer hombre ciego), Don McKellar (Ladrón), Alice Braga (mujer con gafas oscuras), Yoshino Kimura (mujer del primer hombre ciego), Fabiana Gugle (madre del niño), Joe Pingue (conductor de taxi), Susan Coyne (recepcionista), Maury Chakin (contable), Scott Anderson, Isai Rivera Blas.

Color: color.

Duración: 121 minutos.

Género: suspense; drama; ciencia ficción.

Productoras: Niv Fichman. Sonoko Sakai. Andrea Barata Ribeiro. Rhombus Media. Miramax Films. O2 Filmes, Bee Vine Pictures, Movie Central Network, Corus Entertainment, GAGA, Asmik Ace.

Sinopsis: Adaptación de la novela "Ensayo sobre la ceguera", del Premio Nobel portugués José Saramago ${ }^{3}$. Una misteriosa epidemia de ceguera se propaga en todo un país. Las primeras víctimas son recluidas en un hospital sin recibir explicaciones. Entre ellas está una mujer que conserva la vista, pero lo mantiene en secreto para poder acompañar a su marido, que se ha quedado ciego. Dentro del hospital se impone la ley del más fuerte, lo que dará lugar a todo tipo de atrocidades. 


\section{ASPECTOS PSICOLÓGICOS EN PELÍCULAS SOBRE PANDEMIAS. CUANDO “NO SE PUEDE VER (EN) LA PANDEMIA". A CIEGAS (2008), A CIEGAS (2018) \\ M. ${ }^{a}$ PATRICIA ACINAS ACINAS}

Mientras tanto, el caos y el terror dominan las calles. (FILMAFFINITY).

Premios: 2008: Festival de Cannes: Nominada a la Palma de Oro. 2008: Festival de Sitges: Diseño de producción, Premio del público.

\section{Enlaces:}

https://www.filmaffinity.com/es/film224179. $\mathrm{html}$

https://www.imdb.com/title/tt0861689/

Tráiler en español Tráiler en inglés

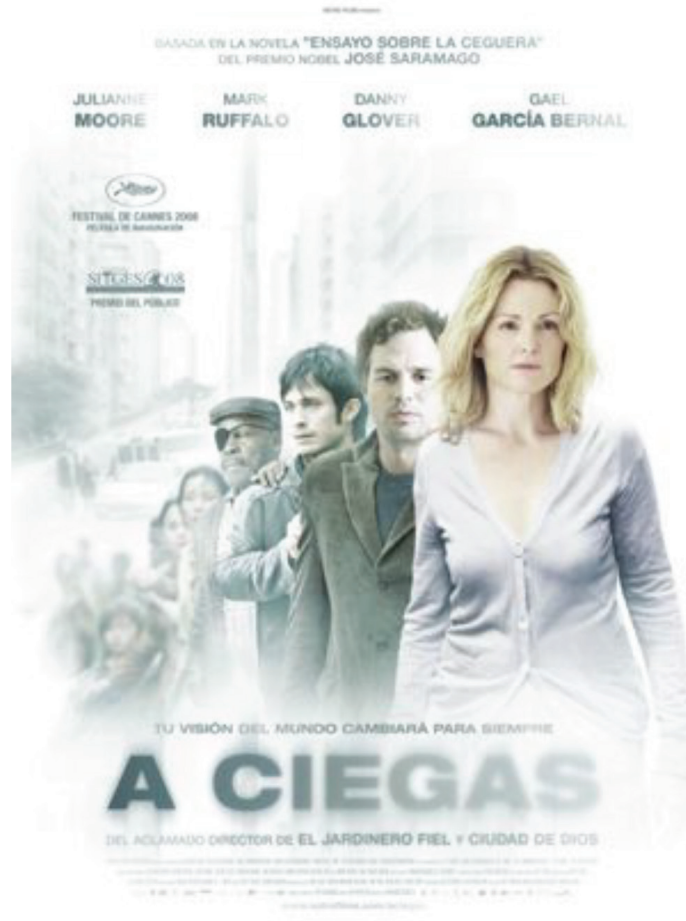

\section{ESTAR CIEGO EN EL MUNDO}

La película es una en la que una epidemia súbita causa la ceguera de los habitantes de una ciudad moderna y que resulta en el colapso de la sociedad. Se la llama la "Enfermedad blanca" y se opone a lo que todos pensamos que es la ceguera, asociado a oscuridad o falta de visión y no ver nada... Se trata de una patología para la que no hay una explicación, que produce incertidumbre, hace más largo nuestro tiempo de reacción, porque va asociada a bloqueo cognitivo y emocional, no saber qué hacer...

Está dirigida por Fernando Meirelles, director brasileño también de otras películas con contenido para reflexionar sobre nuestra existencia, como los filmes El jardinero fiel y Ciudad de Dios, que son dos obras que no dejan indiferente a quien las visiona.

Le costó bastante hacerse con los derechos de la novela del premio nobel José Saramago que había escrito la obra literaria en la que se basa la película, porque el escritor temía que no se hiciera una buena adaptación cinematográfica y se desvirtuara el mensaje de su novela. Curiosamente después de escribir "Ensayo sobre la ceguera" vio la luz la siguientes de sus novelas "Ensayo sobre la lucidez" que parece que nos abre los ojos tras la ceguera "social" de la novela objeto de esta película. Luego el afamado escritor quedo satisfecho del resultado; parece que le costó "ver" que había buenas intenciones en el proyecto de adaptación y que fueron fieles a la obra escrita.

Para acrecentar el sentido de que la pandemia afecta a todos, y que nos cosifica de alguna manera, los personajes en la película no tienen nombre, son una especie de "números", "casos", o "estadísticas". Los personajes se definen por su profesión (médico, cajera,...) o por su relación con un personaje ("mujer del médico"), o por el rol que desempeña ("primer hombre ciego", "jefe del ala 3") o por un atributo de ese personaje ("mujer de gafas oscuras", "viejo con venda negra cubriéndole un ojo"). Esto quiere mostrar el sentido de despersonalización que se produce en las personas en una pandemia o emergencia, en que se les desprovee de su individualidad, de lo que les hace personas únicas e irrepetibles... 


\section{ASPECTOS PSICOLÓGICOS EN PELÍCULAS SOBRE PANDEMIAS. CUANDO “NO SE PUEDE VER (EN) LA PANDEMIA". A CIEGAS (2008), A CIEGAS (2018) \\ M. ${ }^{a}$ PATRICIA ACINAS ACINAS}

En esta película, los protagonistas, no ven (salvo la mujer del médico), y el público, los espectadores sí ven. Por lo tanto, nos convertimos en una especie de voyeurs de una realidad incómoda, que quizás nos apetezca cambiar.

\section{INICIO DE PANDEMIA DE CEGUERA}

Cuando empiezan a aparecer casos de "ceguera" en personas de distintas edades, razas, condición social... se plantean medidas para poder controlar la pandemia. Se parte de que es una enfermedad contagiosa y que requiere aislamiento de los afectados, a los que se les separa de su entorno más inmediato.

Se anuncia por parte de las autoridades que no hay cura y que para evitar la propagación la solución es el aislamiento de las personas afectadas. Se decide tras mucha deliberación, mantener a los afectados en cuarentena, sin contacto físico con el exterior.

El lugar elegido, según la película es una especie de asilo, con toques de hospital psiquiátrico y centro penitenciario, que recuerda en parte a películas como Alguien voló sobre el nido del cuco (1975, Milos Forman), por el ambiente opresivo y asfixiante que emana, o Despertares (1990, Penny Marshall) por la arquitectura y diseño espacial que acompaña a la historia, por citar algunos ejemplos.

Los primeros diagnósticos que se bajaran ante los primeros casos de ceguera, son amaurosis o agnosia visual, que no explican lo sucedido porque no hay deterioro de nervio óptico o las vías nerviosas visuales ni negligencia o falta de reconocimiento visual con preservación de visión. Se podría haber asociado también a cuadros histéricos, conversivos, psicosomáticos, simuladores o incluso trastornos facticios.

A medida que aparecen más casos de manera exponencial en lugares muy distintos del planeta, se declara la epidemia global/pandemia, y el mundo entra en pánico. Cuando se produce una situación de gran Crisis, empieza a reinar el caos, y todos nos preguntamos ¿quién da las órdenes? Si no lo hacen las autoridades con sentido común y humanidad desde el principio, sucede lo que se ve en la película... otras personas intentan sacar provecho de la pandemia con los medios que tienen a su alcance.

Entonces la satisfacción de necesidades básicas como comer se convierte en algo duro y peligroso... Hay que pagar a mafias organizadas, se producen cambios de reglas y normas a discreción de las personas que ostentan el poder de manera formal o informal... Se ven saqueos para conseguir satisfacer necesidades básicas. TRAS 3 DIAS SIN COMER se activan conductas más mediadas por la supervivencia y el cerebro reptiliano, que por la razón y la corteza cerebral.

Estas conductas incluyen reacciones agresivas, violentas descontroladas... como en diversas emergencias ${ }^{4}$ y no hay nadie entre las autoridades que ponga freno o limite a estas conductas. En la película se ve que para poder comer se exigen objetos de valor para dar comida a cambio, y cuando se acaban éstos, se exige el pago "en especie" obligando a las mujeres de otro pabellón a que mantengan relaciones sexuales con los que tienen la comida, y si quedan satisfechos, les darán la comida... Además, se raciona, lo que en un primer momento eran cuatro cajas de comida, se convierten en tres, que son las que se dan finalmente. Las conductas agresivas y violentas, se multiplican para satisfacer esas necesidades básicas de primer escalón que diría Maslow. Y una mujer que se ofreció para mantener relaciones sexuales y que dieran comida a su pabellón es violada y golpeada hasta la muerte, y expuesta a vejaciones, risas, desprecio y diversas formas de maltrato psicológico, ambiental... Y como puntilla final aparece ese cinismo de quien tiene el poder de extorsionar y hacer daño "¿Se ha muerto alguien?"

En general las condiciones higiénico-sanitarias del lugar dejan mucho que desear, son precarias en todos los sentidos, por ejemplo, 


\section{ASPECTOS PSICOLÓGICOS EN PELÍCULAS SOBRE PANDEMIAS. CUANDO “NO SE PUEDE VER (EN) LA PANDEMIA". A CIEGAS (2008), A CIEGAS (2018) \\ M. ${ }^{a}$ PATRICIA ACINAS ACINAS}

se les acaba el jabón y no pueden asearse... Leyendo las notas de rodaje se comenta que el equipo de arte, planteó 3-4 momentos de deterioro progresivo del centro donde se encuentran recluidos, para hacer más realista la historia. Este deterioro de las instalaciones es paralelo al deterioro de las relaciones entre las personas dentro de esas paredes y el de las reacciones de algunas personas que son cuando menos poco empáticas, hacia el malestar y sufrimiento de otros congéneres. Aparecen desde el principio una serie de normas que se repiten por altavoces, para explicar el funcionamiento del lugar donde han sido confinados todos los afectados. Se supone que hay un control remoto teledirigido y vigilado por pantallas de los ciegos; pero nada más. En ningún momento se ve supervisión in situ, en los pabellones para garantizar la seguridad y facilitar las cosas a los que estén más perjudicados por la ceguera. Esto trasluce deshumanidad y deshumanización, y nos lleva a nuestro mundo moderno que adolece de falta de estas características.

La vida en el interior del recinto se vuelve complicada, se asemeja a las características de un campo de concentración (de los que habría películas de sobra para mostrar una imagen iconográfica al respecto; pero no lo vamos a hacer porque daría para otro artículo completo). Se ven las colas para conseguir bienes de primera necesidad, controles en las entradas, escaleras...

Entre las atribuciones causales que diríamos en psicología, que nos indican las explicaciones que se dan las personas o las instituciones ante una situación de catástrofe, pandemia, en la película encontramos varias: castigo divino global, para todos ("Dios nos está castigando con lo que está sucediendo"), contagio por conducta personal inapropiada.... Hasta que se aclaran las causas, muchas de las explicaciones que se dan, suelen resultar erróneas.

Siempre aparece, al principio de una emergencia sanitaria, la idea de la inexplicabilidad del hecho, ante el desconocimiento de lo que está sucediendo:...

Médico: No puedo ver.// No veo. Me lo habrá contagiado el paciente de ayera.

Mujer del médico: Es imposible, nadie queda ciego por contagio.

En función de las atribuciones causales o de lo que considera la etiología del problema de salud emergente, se toman las medidas oportunas. En muchas ocasiones surgen conflictos entre Decisiones institucionales vs decisiones personales estando afectado/a.

Por otro lado, están las percepciones o impresiones más cognitivas de lo que me ha sucedido y cómo hablo de ello. No podemos olvidar que, de alguna manera el lenguaje marca nuestra manera de ver el mundo. No es lo mismo decir "me han robado la vista", que "he perdido la vista", o "no puedo ver". Todo esto también nos permite saber cómo está viviendo la persona la situación de crisis (Foto 1).

\section{QUÉ IMPLICA ESTAR CIEGA PARA UNA PERSONA}

Al no poder ver las personas deben interpretar otras señales sensoriales, como los sonidos, olores, otras percepciones más cinestésicas, propioceptivas, incluso... Puede ocurrir que algunos estímulos sean ambiguos y no está claro que deba hacerse al respecto, por ejemplo, ante ruidos que pueden resultar amenazantes o señales de peligro.

a. En inglés (I can't see = No puedo ver/No veo). La traducción en la versión latina y castellana, respectivamente. En otras versiones se ha traducido como "Estoy ciego". Esto plantea matices en cómo se vive la situación: "no poder hacer algo", "Ios ojos no ejercen la función de ver", o "estado/resultado/interpretación" = estoy ciego (en las tres posibilidades de traducción). 


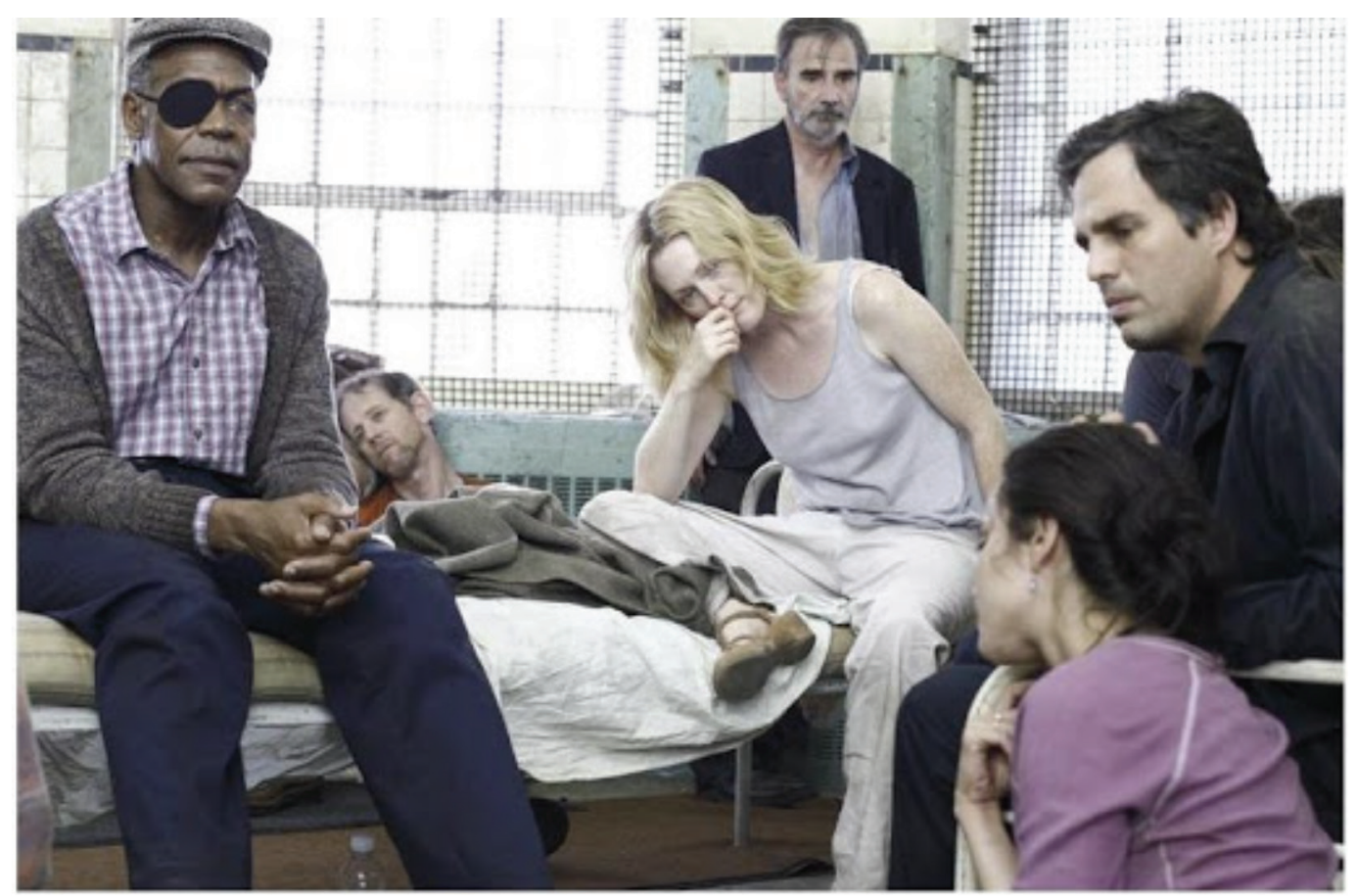

Foto 1. Personajes principales (viejo con una venda cubriendo un ojo, mujer del médico, médico) y otros personajes secundarios, pensando qué hacer ante presiones de internos de la sala 3.

Algunas tareas más o menos cotidianas se complican, como ir al baño, aseo personal... y en muchos casos requieren ayuda de terceras personas, pero en este caso son personas invidentes también. Saber la hora (el reloj de pulsera no es útil), pero tampoco los letreros indicativos en cualquier espacio cerrado; hay que tantear con las manos o con el cuerpo, por donde vamos y si es seguro para cada uno de nosotros.

$\mathrm{Y}$ otras tareas se vuelven imposibles, como conducir (el primer hombre que se queda ciego lo hace en el curso de un desplazamiento conduciendo). Pero también se encuentran estrategias, como crear un "mapa mental" del lugar con varios hitos que permitan orientarse por tacto o por olor, incluso. Contar las escaleras para saber dónde nos llevan o donde estamos...

Al hecho de no poder ver, se une la estigmatización, ser apartado, como un apestado, como se ha hecho en otras épocas con los apestados, tuberculosos, o con cualquier otra enfermedad infectocontagiosa.

Resulta llamativo que dentro del bando de los "mafiosos" se encuentra un contable ciego por causas orgánicas previas al internamiento, que es poco comprensivo con las personas que han perdido la visión durante la pandemia. El Doctor (personaje de Mark Ruffalo) escucha una máquina para escribir en braille, y se da cuenta de que hay un ciego "auténtico" que saca provecho de que los otros lo estén, porque ha aprendido ya 


\section{ASPECTOS PSICOLÓGICOS EN PELÍCULAS SOBRE PANDEMIAS. CUANDO “NO SE PUEDE VER (EN) LA PANDEMIA". A CIEGAS (2008), A CIEGAS (2018) \\ M. ${ }^{a}$ PATRICIA ACINAS ACINAS}

antes a desenvolverse en un mundo sin visión (en lugar de ser proactivo, altruista...).

Pero no todo son conductas deplorables, también hay conductas positivas hacia otras personas, como en cualquier emergencia o catástrofe, en lo que se llama la fase de "luna de miel" ${ }^{5}$ en que se brinda ayuda a los que la necesitan, se comparte lo poco que se tiene. En la película, por ejemplo, se ayuda a una persona herida que ha sido disparada por otro ciego (parece tener bastante puntería a pesar de no ver por la enfermedad blanca), compartir comida en el comedor, repartir armas (cuchillos) cuando es necesario... la radio que tiene uno de ellos y que les brinda información del exterior y que es útil para desenvolverse en el interior.

Esto se ve contrarrestado con la ayuda exterior de las autoridades o el gobierno, que brilla por su ausencia, porque permite los pillajes, uso fraudulento de enseres básicos.... No hay contacto con el exterior, apenas hay información de cómo están otras personas. La radio clandestina es lo único que mantiene a las personas informadas.

Por otro lado, la organización interna de algunos pabellones, como el del médico y su esposa, permite mantener algunas cuestiones controladas y se reparten tareas, en las asambleas periódicas. Aunque no siempre sea del agrado de todos. Se aprecia fácilmente cuando matan a algunos de los ciegos que vienen en remesas posteriores y se plantea que como hay tres muertos, cada pabellón se encargue de enterrar el cuerpo de cada uno.

La violencia que aparece en la película de manera más o menos implícita, cuando se extorsiona a otros para acceder a bienes y servicios básicos, se vuelve en contra de quien la ejerce. Los hombres de la mafia organizada que solicitan los favores sexuales de las mujeres de otra ala, y terminan por matar a la mujer, luego son pagados con la misma moneda. Digamos que la violencia se vuelve contra ellos, porque alguna mujer (la mujer del médico) empieza a tomar la justicia por su mano y llega a amenazar y matar a un hombre (con una puñalada en el abdomen) y luego añade una amenaza: "Por cada día que nos dejes sin comer uno de tus hombres morirá". Esto produce una escalada de violencia. El propio doctor se lo advierte a su mujer "Va a comenzar la guerra".

Cuando avanza la emergencia y al salir "libres" en la "postemergencia", se ve que continúan los saqueos en supermercados y demás por conseguir lo básico para sobrevivir. La mujer del médico consigue comida y el doctor, ropa; pero están a punto de perder la vida por la violencia con la que intentan quitarles lo que han conseguido. Esto también podemos verlo en otras grandes emergencias cuando hay escasez de recursos ${ }^{5}$.

\section{VER CUANDO OTROS NO PUEDEN VER}

Dentro de este mundo de "ciegos" hay una persona "vidente" (en su doble acepción de "poder ver conservando el sentido de la vista" y "ver más allá, ver el futuro", "ver soluciones a los problemas"). Se trata de la mujer del doctor oftalmólogo. Es ella la que verbaliza las frases más profundas e inteligentes de la película.

Ante la explosión de la pandemia ella decide no separarse de su marido y decir que está ciega también. De hecho, también le transmite al resto de los recluidos que es ciega, hasta que algunos lo descubren. $Y$ las reacciones son de lo mas variado, desde quienes se sienten engañados, los que la culpabilizan y los que valoran su ayuda al tener conservada la vista.

Médico: ¿Tienes miedo a cerrar los ojos?

Mujer: Tengo miedo a abrirlos.

En la escena tras la pelea entre pabellones o alas del hospital:

Hombre responsable de ala 3: Nunca olvidaré su voz.

Mujer del médico: Yo nunca olvidaré su rostro. 


\section{ASPECTOS PSICOLÓGICOS EN PELÍCULAS SOBRE PANDEMIAS. CUANDO “NO SE PUEDE VER (EN) LA PANDEMIA". A CIEGAS (2008), A CIEGAS (2018) \\ M. ${ }^{a}$ PATRICIA ACINAS ACINAS}

Cuando perdemos la vista otros sentidos se agudizan, reconocer a las personas por la voz, por los matices vocales, estar al tanto de otras señales que podemos captar a través de los sentidos.

"Solo hay algo peor que la ceguera, es ser la única que puede ver" (mujer del médico).

Su personaje tiene un rol proactivo y cuidador de otros que están sin visión; ella es la que encuentra solución a los problemas de convivencia y logísticos. También en ella se ve claramente un proceso de adaptación a las condiciones de supervivencia extrema, un cambio en sus valores morales. Por ejemplo, cuando para poder comer exigen primero pago con objetos de valor (ella recolecta las joyas y demás) o que vayan mujeres a mantener relaciones con los del otro pabellón (ella se ofrece voluntaria, su marido previamente le ha dado la libertad públicamente para que elija lo que considere). Incluso se puede decir que subyace algo en la línea de el "sacrificio del líder" por una causa común comunitaria.

En condiciones críticas y para seguir viviendo a toda costa, aceptamos vejaciones y humillaciones, hacer el ridículo, chocar con muros (literalmente en la película), seguir a otros para tener "sentido de pertenencia grupal" y no sentirnos "solos ante el peligro" y la incertidumbre que produce una situación inesperada e incontrolable. Seguimos ese "tintineo" que se ve en la película, que nos puede guiar en algunos momentos, pero en otros nos conduce a un abismo del que no podemos salir. Esto nos quita nuestra propia identidad como personas.

Aquí se nos plantea la tesitura de "tener ojos", "abrir los ojos" cuando otros los pierden. $Y$ que esto puede ser una gran responsabilidad, por un lado, y por otro una carga muy dolorosa en muchas ocasiones. A veces es difícil transmitir a quien corresponde lo que se está viendo que va a suceder y se "ven" soluciones a los problemas que quien puede hacer algo al respecto no hace...

\section{PODER VER DE NUEVO ¿SERÁ POSIBLE?}

Cuando se ve una salida dentro del edificio donde se encuentran los protagonistas, se plantean varias dicotomías, entre volver a casa y la propia seguridad. Y en algunos personajes empiezan a verse ventajas de estar ciego (a lo mejor en algún momento está bien no ver ciertas cosas que nos hacen daño y no podemos solucionar en la vida). Cuando llegan a la casa el médico y su esposa, con las personas a las que ofrecen que les acompañen, alguien dice que ser ciego tiene sus ventajas, que ahora están "juntos" y que "nunca ha estado mejor...", "Parece que la ceguera es un regalo para algunos".

Al final de la película se vislumbra el concepto de Esperanza. Tras estar prácticamente toda la película sin ver, la primera persona que se quedó ciega (el hombre con rasgos orientales) empieza a ver.

Pero también debemos adaptarnos a la luz (a la realidad, a la verdad) tras un periodo prolongado de oscuridad, (de ceguera), para poder recuperar la vista en condiciones y con garantías de que sea funcional.

La tranquilidad y confianza en poder recuperar la vida, hace acto de presencia en estos momentos. Puede ser una metáfora para empezar a ver las cosas con otros ojos, después de lo vivido.

También esto nos puede llevar a un debate de si creemos o no en nuestras estructuras sociales, si nos sostienen, si podemos confiar en ellas, o en el modelo de sociedad que hemos diseñado y en el que estamos inmersos (Foto 2).

Tanto la novela como la película nos permiten reflexionar sobre nuestra sociedad y sobre nosotros mismos, sobre lo que vemos y no vemos, lo que deberíamos ver...

\section{A CIEGAS (2018): LAS VOCES PUEDEN AYUDARNOS O CONFUNDIRNOS.}

\section{Ficha técnica}

Título: A ciegas.

Titulo original: Bird Box. Otros títulos: Bird Box: a ciegas (Hispanoamérica). 


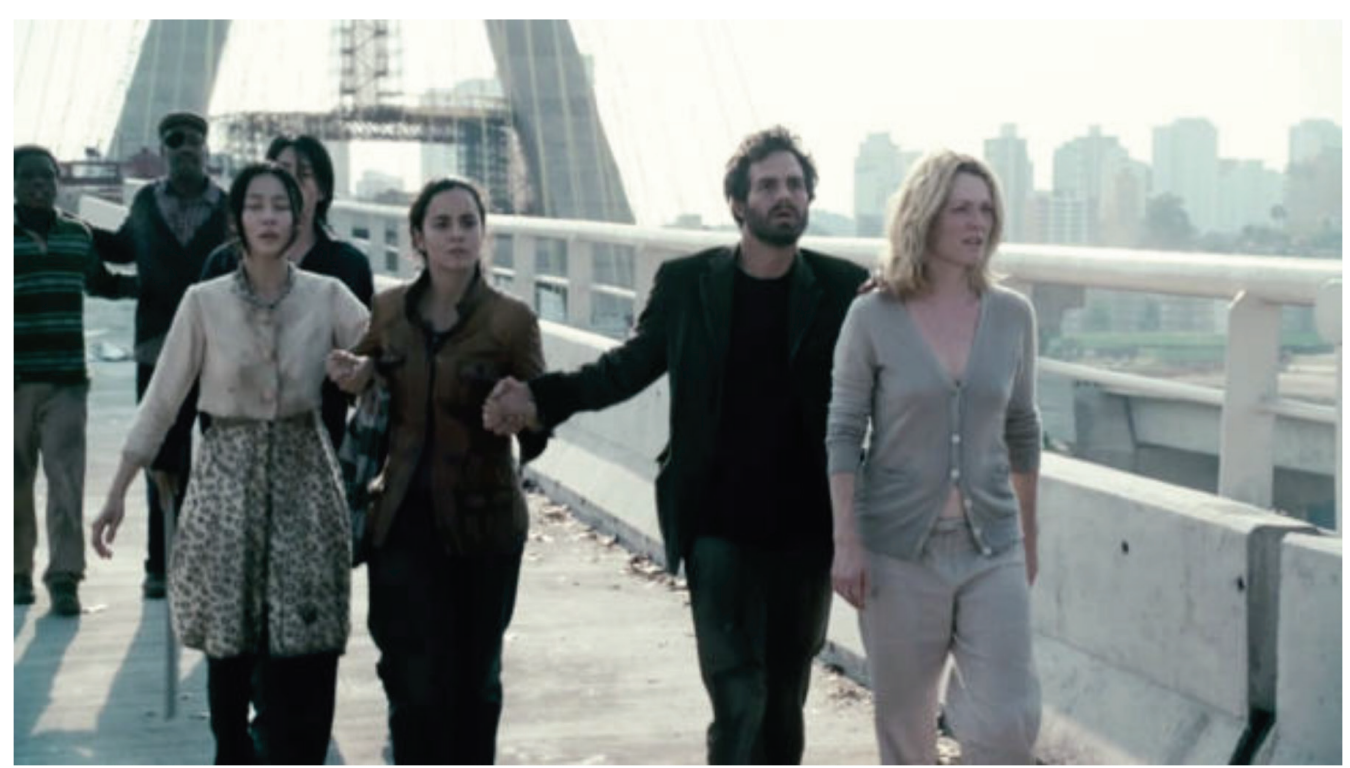

Foto 2. Supervivientes del confinamiento, salen a la luz, guiados por la mujer del médico, agarrados de las manos. Sólo puede ver ella.

País: EE. UU.

Año: 2018.

Director: Susanne Bier.

Música: Trent Reznor, Atticus Ross.

Fotografía: Salvatore Totino.

Montaje: Ben Lester.

Guion: Eric Heisserer (basado en la Novela de Josh Malerman) ${ }^{6}$

Intérpretes: Sandra Bullock (Malorie Hayes), Trevante Rhodes (Tom), John Malkovich (Douglas), Sarah Paulson (Jessica), Jacki Weaver (Cheryl), Danielle Macdonald (Olympia), Julian Edwards (Tom niño), Vivien Lyra Blair (Olympia niña), Rosa Salazar (Lucy), BD Wong (Greg), Tom Hollander (Gary), Machine Gun Kelly (Félix), David Dastmalchian (Merodeador que silba), Lil Rel Howery (Charlie), Happy Anderson (el hombre del río), Amy Gumenick (Samantha), Parminder Nagra (Dra. Lapham), Taylor Handley (Jason), Rebecca Pidgeon
(Lydia), Keith Jardine, Chanon Finley, Damon O'Daniel, Matt Leonard.

Duración: 124 minutos.

Género: Terror. Ciencia ficción.

Productoras: Netflix. Universal Pictures, Chris Morgan Productions, Bluegrass Films.

Sinopsis: "Un lustro después de que una misteriosa presencia sobrenatural llevara al suicidio a una gran parte de la sociedad, una de las supervivientes, Malorie Hayes (Sandra Bullock), y sus dos hijos, buscan desesperadamente el modo de salvarse río abajo, en una pequeña barca, hacia un lugar seguro". (FILMAFFINITY).

Premios: MTV Movie Award a Mejor Actuación Asustada.

\section{Enlaces:}

https://www.filmaffinity.com/es/film519772. html https://www.imdb.com/title/tt2737304/ 
Tráiler en español

Tráiler en inglés

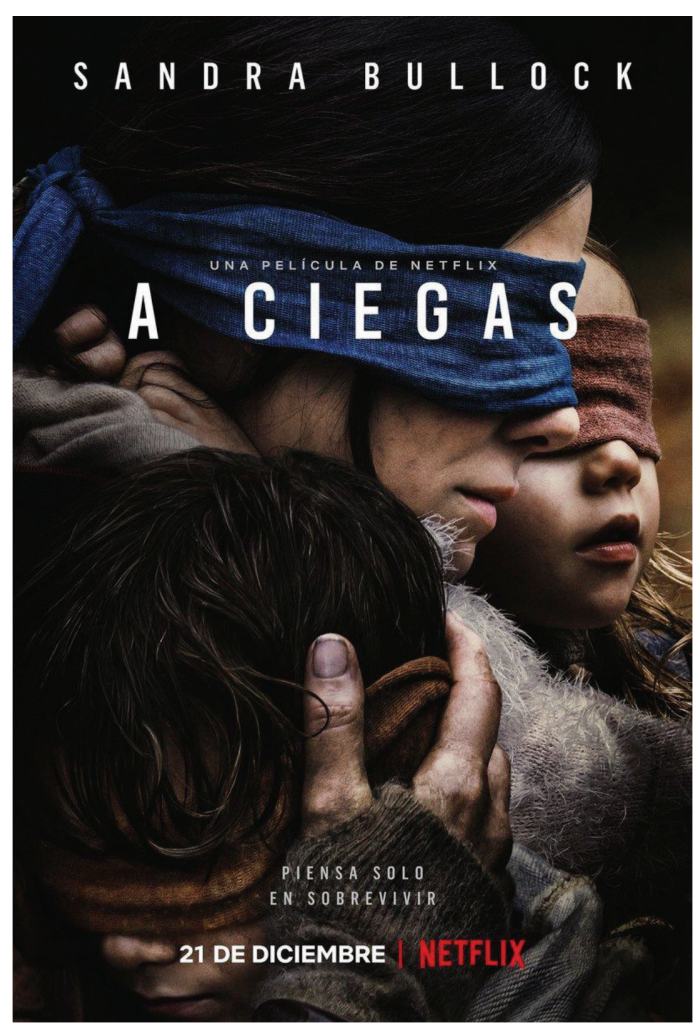

\section{DESORIENTADOS EN TIEMPO Y ESPACIO}

La película de Netflix nos traslada a un Futuro postapocalíptico en el que aparecen elementos de supervivencia dentro de un mundo sobrenatural. La película está narrada alternando elementos de la historia del presente (huida hacia el río) con elementos del pasado (cinco años atrás, cuando se declaró la pandemia).

En esta película, por contraposición a la anterior, colocarse la venda es algo voluntario, y protege del contagio, y de la autodestrucción. Aquí hay posibilidad de ver de nuevo a intervalos cuando se está en un entorno seguro. No es una pérdida permanente de la visión.
Podemos saber cuándo una persona ha sido poseída y va a matar o morirse por su propia mano, cuando aparecen los ojos rojos, ensangrentados; entonces entendemos cuando ha sido captada por los entes la persona en cuestión.

\section{PANORAMA DESOLADOR}

Casi al principio de la película escuchamos noticias que informan de suicidios en masa y evacuaciones masivas en aeropuertos y estaciones. Como suele suceder en la vida real, pensamos que no nos puede suceder. Malorie le dice a su hermana: "No me afecta, es en Rusia". Hasta que regresan de la ecografía y ven lo que les sucede a las personas, como si se hubieran vuelto locas de repente.

Sabemos que la profesión de la protagonista es pintora (la vemos embarazada dando retoques a un cuadro). Nos damos cuenta de que para su profesión, la vista es importante y está a punto de tener que anular ese sentido para poder seguir viviendo. Parece el fin del mundo y una sucesión de muertes que no se pueden parar.

Los inicios de cómo se extiende pandemia nos llevan a una mujer en un hospital que da cabezazos con el cristal (cuando salen de la ecografía); antes estaba tranquila hablando por teléfono (cuando iban a hacer la ecografía), Inmediatamente después ve como su hermana, hablando y bromeando con ella, de repente se pone seria y conduce como si estuviera poseída y se chocan/salida de vía teniendo un accidente de tráfico. Y luego presencia como se deja arrollar por un camión y sus manos manchadas de sangre (10:30"), aparece el caos en las personas, revueltas ciudadanas, más accidentes en masa y en cadena...

En estas circunstancias lo que se ve en la película que se activa es el miedo a que suceda a más víctimas, el miedo a morir, el miedo a lo desconocido, que además hace que te suicides y autolesiones. 


\section{ASPECTOS PSICOLÓGICOS EN PELÍCULAS SOBRE PANDEMIAS. CUANDO “NO SE PUEDE VER (EN) LA PANDEMIA". A CIEGAS (2008), A CIEGAS (2018) \\ M. ${ }^{a}$ PATRICIA ACINAS ACINAS}

Ante esto lo que prima es tomar medidas para no ser presa de lo desconocido que mata sin piedad: cerrar ventanas, no salir a la calle, no mirar a las cosas,... no permitir que otras personas entren, taparse los ojos...

Se activa nuestro cerebro en modo de supervivencia y la urgencia de conseguir víveres sin poder ver se hace complejo, "podemos ver mejor de lo que pensamos". "no podemos mirarlos directamente, pero si con un reproductor que es pixeles y calor" (comentan dos de los varones de la casa que luego fallecen).

La estrategia de ver las imágenes a través de las videocámaras y transformar en calor, es similar al mito de la medusa (o al menos lo recuerda). Consiguieron vencerla viendo su imagen a través de un espejo para no mirarla directamente, pero en la película no funciona, tienen que entrar y destruir el monitor. $Y$ el chico que tuvo la idea fallece, quitándose la vida a pesar de las contenciones en muñecas.

Además se nombran creencias antropológicas ancestrales de diversas culturas (China, India...), que producen miedo, y que hablan de que lo que sea se apodera de los miedos, tristezas y pérdida de cada uno, que es lo que está pasando en ese momento (la amenaza que saben que existe).

Cuando pasan las cosas, como si de una plaga se tratara... lo que queda es un paisaje desolado, donde se ha sembrado la muerte y destrucción.

Es fundamental saber qué tácticas y estrategias se pueden poner en marcha... Salir a buscar comida, conducir a ciegas, con el GPS y tapando las ventanas... prestar atención a las señales, (que no está claro si es un badén, o una persona muerta en el suelo, u otro coche o, incluso las cosas que producen miedo... Todo esto son tareas de pura supervivencia y afrontamiento de una amenaza tan real como invisible.

En la película también se aprecia como se afanan en coger productos de primera necesidad, no perecederos, alcohol, golosinas, electrónica, conservas..., papel higiénico, según la persona (cada uno tiene sus prioridades y esto habla de las necesidades de cada uno en situaciones límite). Uno de los personajes (Douglas), propone quedarse allí, por tener provisiones aseguradas. $Y$ esto nos habla de lo fundamental que se considera el aprovisionamiento y el miedo a quedarse sin alimentos y objetos fundamentales para la supervivencia en condiciones de este tipo.

\section{INSTINTO DE SUPERVIVENCIA E INSTINTO MATERNAL}

A lo largo de toda la película se hace referencia a estos dos aspectos. Sobrevivir en un entorno hostil, donde no puedes ver al enemigo (esas voces o esas "cosas" que se alimentan de nuestros miedos y nos destruyen por dentro).

Cuando vemos la película descubrimos que la protagonista está embarazada pero no tiene mucho ánimo por cuidar a ese niño; la ginecóloga le llega a ofrecer información para dar en adopción al bebé que trae (cree que es una niña, pero a lo largo de la película descubrimos que es un niño). La evolución del personaje pasa de no querer ser madre (parece una madre soltera obligada por las circunstancias) a defender acérrimamente la vida de su hijo y de otro niño con misma fecha de nacimiento, en ocasiones a costa de su propia vida, cuando las cosas amenazan y ella suplica que por lo menos, dejen entrar a los niños.

El personaje de Sandra Bullock (también productora de la película junto a la directora del filme) es el de una madre preocupada porque no le arrebaten a los hijos. pide a las criaturas que no se lleven a sus hijos y cuando se siente cuestionada en sus actuaciones en los 5 años que dura la situación, como cuando discute con Tom, justifica que está movida por ese instinto maternal. "Cada decisión que tomé en mi vida fue por ellos".

Al principio es una madre que da normas a sus niños sobre cómo comportarse y normas de seguridad para conservar la vida ante la amenaza exterior. Explica cómo hacer recorrido de 
evacuación voluntaria, pero debe hacerse con cierta inseguridad, a tientas y con poca información a nivel visual y en general.

Cuando emprenden el viaje a través del río con los niños, (evacuación a otro lugar), las normas de seguridad son contundentes "si escucháis algo en el bosque, decídmelo" en el agua... me avisáis" No os podéis quitar la venda bajo ninguna circunstancia (prima la protección a si misma y a otros, y velar por la propia vida y la de demás). Esto se repite en dos ocasiones a lo largo de la película. En los minutos 3:58" (se retoman algunas frases en $1 \mathrm{~h} 39^{\prime}: 55^{\prime \prime}$ donde les da las mismas instrucciones antes de ir al río) (Foto 3).

Hay otros momentos de dar normas a otros, por seguridad de todos. Nuevas normas de seguridad a los niños y 57:36" y $1 \mathrm{~h} 12^{\prime}: 30^{\prime \prime}$ cuando les habla de que alguien tiene que mirar tras los rápidos para que puedan pasar todos (escena que se vuelve a repetir en $1 \mathrm{~h} 41^{\prime}: 10^{\prime \prime}$ ) y finalmente decide "No va mirar nadie" (y lo repite), confiando en que no va a ser necesario este riesgo. Esto refuerza por supuesto la idea de seguir a ciegas.

La conducta suicida no voluntaria, sino inducida, es algo que está presente en las muertes que se van sucediendo en la pantalla. Y surgen las culpabilidades cruzadas, por ejemplo, Douglas (el personaje de John Malkovich) le increpa a Malorie tras la revuelta, cuando la mujer la quiere ayudar al verla embarazada y luego es poseída por las cosas y muere: Ha querido ayudarte y ahora está muerta.

En la película, cualquier actividad implica preguntarse si es necesario cerrar los ojos o ponerse la venda para garantizar la propia integridad física. Esto es un estrés añadido ante el riesgo de ser presa de las cosas que terminan empujando al suicidio.

Las explicaciones y atribuciones, para tratar de entender lo que sucede son diversas: "No es

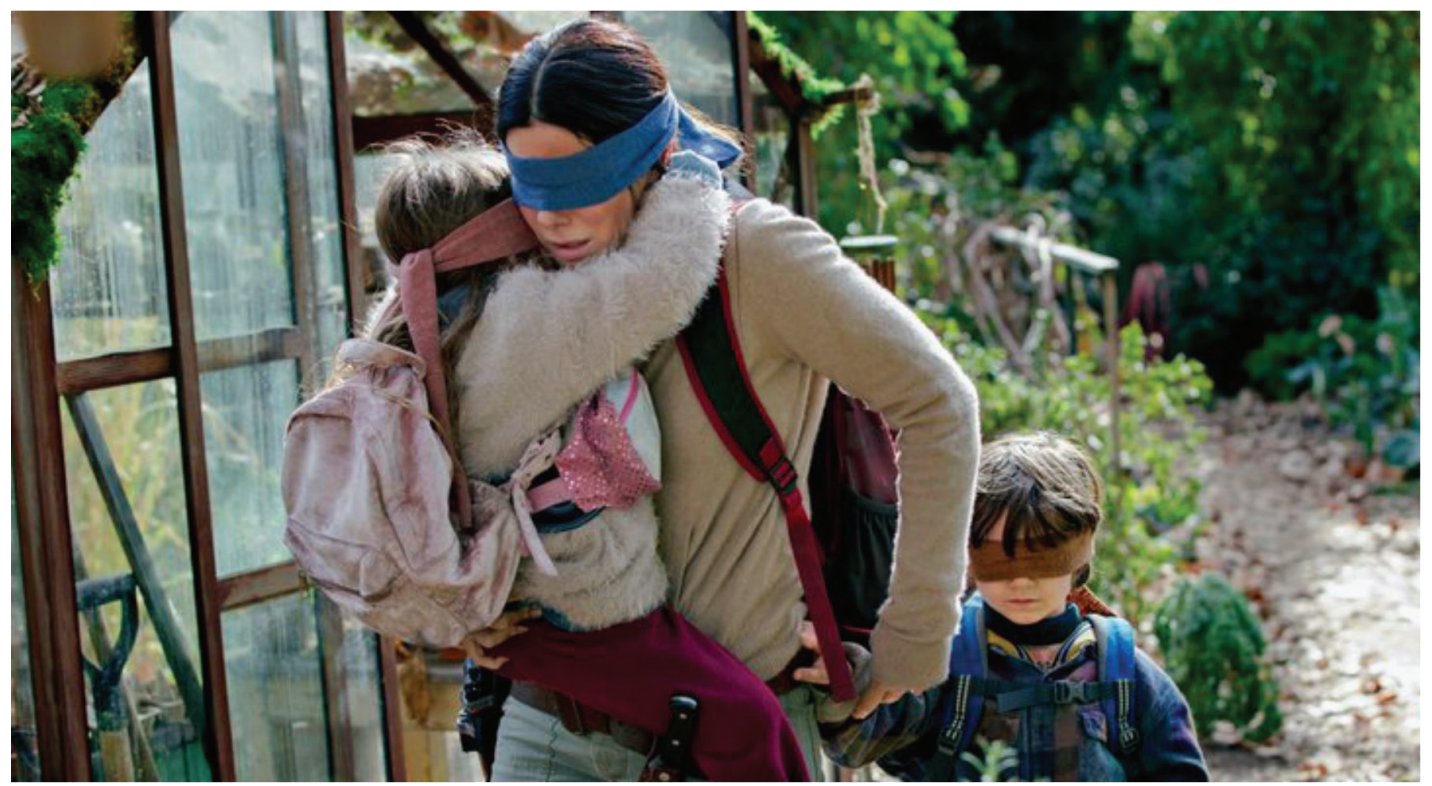

Foto 3. Malorie lleva a los niños a coger la barca, todos con venda en los ojos, para no ver a las "cosas". 


\section{ASPECTOS PSICOLÓGICOS EN PELÍCULAS SOBRE PANDEMIAS. CUANDO “NO SE PUEDE VER (EN) LA PANDEMIA". A CIEGAS (2008), A CIEGAS (2018) \\ M. ${ }^{a}$ PATRICIA ACINAS ACINAS}

un virus o un ataque químico, es pura maldad", "la gente describe una entidad que adopta la forma de tus miedos".

La gente dice que es un ser transformado en tu peor pesadilla. // Todo el contacto que hemos tenido con el exterior nos ha traído la muerte. (Douglas), Las criaturas, "se fueron- Cierren los ojos, aguanten" (Tom en el parking).

Tus hijos merecen esperanza (Tom a Malorie).

"Sobrevivir no es vivir", "Los niños necesitan sueños, amor, esperanza, una madre" (Tom).

\section{SUICIDIO EN UNA PANDEMIA}

La conducta suicida siempre ha estado rodeada de un halo de misterio, estigma, y está considerada como una de las muertes más difíciles de asimilar y uno de los duelos más complejos que existen ${ }^{7}$. Es traumático presenciar la muerte de alguien, que ve algo aterrador y cambia de comportamiento, y se convierte en una persona triste... En la película se ve como hay conductas extrañas o inexplicables de seres queridos o personas alrededor (golpearse contra un cristal, accidentes de coche espectaculares, incendios, gente corriendo, tumultos y revueltas callejeras, ver otros seres vivos y animales con comportamientos extraños e inesperados...). Por lo tanto, se da pie al miedo a que me suceda, por el contagio, miedo a estar loca o a ser calificada como tal.

Todas estas variables añadidas (presenciar muerte, que sea un ser querido casi irreconocible en su conducta), añaden más malestar psicológico y sufrimiento existencial.

Cuando se inicia el viaje para llegar al lugar seguro, se ve la gran bruma en el río apenas se ve nada; esto, añadido a las vendas, y que hay voces que parece que van a ayudar (pero no lo hacen). Malorie desconfía y les dice a los niños que no se quiten las vendas. Las frases que se escuchan en esos momentos, son muy tentadoras: "Quitaos la venda, purificará el mundo, todos tenemos que mirar".
La frase "Abre los ojos" se repite en el bosque y en la mente de las personas afectadas futuras víctimas de la pandemia (al ver la frase es inevitable hacer referencia a película de Amenábar, en la que nos invitaban a salir de un mundo creado artificialmente).

Lo que el espectador deduce es que lo que se ve es lo terrorífico, lo que asusta, lo que no se quiere ver $y$ hace que nos enfrentemos a nuestros miedos y pesadillas. No se puede contar a otros lo que se ha visto. "Si lo miras, se transforma en tu peor miedo".

En la película se aprecia lo difícil que resulta diferenciar una persona real pidiendo ayuda o voces/o la cosa que quiere provocar la autodestrucción. Salvar la vida, se convierte en una prioridad.

Vemos varios casos de suicidio altruista, sacrificándose por los demás para que salven la vida y no mueran. Cuando va a entrar alguien peligroso a la casa, sale fuera y entretiene a la cosa para que los demás puedan estar seguros. En otro momento, Tom, para proteger a Malorie y los niños, les dice que se vayan adelantando y si tarda más de 15 minutos, se vayan en el barco. Se enfrenta a las cosas y los otros tres pueden seguir su camino.

Las conductas autolíticas son muy variadas; dejarse arrollar, por vehículo pesado, defenestración, disparo en mentón, clavarse objetos punzantes como tijeras... Oscilan desde suicidio por miedo, suicidio colectivo, cuando hay varias personas que lo hacen al mismo tiempo, como si de una secta se tratara.... Lo que se ve en las imágenes es una inducción al suicidio, que es un delito tipificado en el código penal.

\section{CONCLUSIONES}

Estas películas sobre la ceguera, con mismo título en castellano pero distinto título en inglés, 


\section{ASPECTOS PSICOLÓGICOS EN PELÍCULAS SOBRE PANDEMIAS. CUANDO "NO SE PUEDE VER (EN) LA PANDEMIA". A CIEGAS (2008), A CIEGAS (2018) \\ M. ${ }^{a}$ PATRICIA ACINAS ACINAS}

en la versión original, nos permiten sacar algunas enseñanzas para la vida:

Nos hablan en sentido metafórico, de que no vemos algunas cosas que están sucediendo, y que a veces tiene que pasar algo para que "veamos". Esto está relacionado con la idea de que debemos cambiar la visión del mundo.

Ante una situación de pérdida de un sentido vital para nuestra vida cotidiana, se activan sensaciones de vulnerabilidad, indefensión (incluida indefensión aprendida) y surge la petición de ayuda a quienes consideramos que están en condiciones de brindarnos esa ayuda. La indefensión es doble por ser privado de un sentido y por no saber qué va a suceder y estar a expensas de lo que suceda posteriormente $\mathrm{o}$ a las decisiones que se tomen por parte de las autoridades sanitarias, civiles, políticas...

Las películas nos hablan del blanco y negro, de nuestras luces y sombras, y de que debemos potenciar nuestras luces, para iluminar nuestro camino, pero también conociendo que hay sombras y zonas de peligro que se deben respetar también y tener en cuenta (no podemos eliminar las sombras, pero si conocer donde están para que no nos nublen la vista que conservamos).

Las películas nos hacen conectar con lo que supone el estigma por ser diferente o tener una discapacidad en la época actual. A veces no comprendemos totalmente a las personas con diversidad funcional, o con capacidades especiales. Estas películas son una buena manera, didáctica también, para ponerse en el lugar de estas personas.

Estas obras cinematográficas nos ponen en la cuerda floja planteando el difícil equilibrio que se produce entre supervivencia y moralidad, en situaciones límite, de emergencia continuada, de pandemia, o de precariedad de recursos. Y como esto puede dar lugar a conductas que no estarían presentes en otros momentos de la vida de estas personas. Es muy posible que cuando las personas valoren lo que han hecho (ya fuera de la situación vivida) se sientan culpables, sucias, malas personas...

Por esto motivo no está de más, plasmar aquí una máxima que tenemos en psicología de emergencias: "Se trata de reacciones normales en personas normales ante situaciones anormales". Es la situación excepcional la que nos empuja a comportarnos de manera distinta, a veces de forma contraactitudinal y opuesta a nuestros valores y moralidad.

También podemos sacar como conclusiones la importancia de "tender puentes" de manera simbólica cuando se producen estas situaciones. En la película de 2008 se hace también de manera literal, además de metafórica, cuando al final salen del confinamiento y atraviesan el puente colgante, en fila, uno detrás de otro, como una liberación. Para contrarrestar la escalada de violencia, que se ve en la película. También "buscar salidas viables" en las circunstancias en que se produce la situación límite en la que estamos inmersos.

Otra enseñanza que se extrae es que somos interdependientes como seres humanos; dependemos unos de otros para sobrevivir en determinados momentos difíciles. La unidad es importante para luchar contra el enemigo externo, que llamamos enfermedad en una pandemia.

Ambas películas abogan por que nos quitemos la venda, el antifaz con el que vivimos encorsetados en algunos momentos por unas convenciones sociales que quizás hemos aceptado sin haber elegido y que, si nos las planteamos, a lo mejor no estamos tan de acuerdo, y podemos hacer algo por cambiarlas.

Cuando hay ceguera y oscuridad, hay que saber guiarse por voces apropiadas, autorizadas, constructivas,... Debemos saber discernir, qué "voces" cumplen con estas características y otorgarles nuestra aprobación.

\section{VENDRÁ LA MUERTE Y TENDRÁ TUS OJOS}

Vendrá la muerte y tendrá tus ojos, esta muerte que nos acompaña 


\section{ASPECTOS PSICOLÓGICOS EN PELÍCULAS SOBRE PANDEMIAS. CUANDO “NO SE PUEDE VER (EN) LA PANDEMIA". A CIEGAS (2008), A CIEGAS (2018) \\ M. ${ }^{a}$ PATRICIA ACINAS ACINAS}

desde el alba a la noche, insomne, sorda, como un viejo remordimiento o un absurdo defecto. Tus ojos serán una palabra inútil, un grito callado, un silencio.

Así los ves cada mañana cuando sola te inclinas ante el espejo. Oh, cara esperanza, aquel día sabremos, también, que eres la vida y eres la nada.

Para todos tiene la muerte una mirada. Vendrá la muerte y tendrá tus ojos.

Será como dejar un vicio, como ver en el espejo asomar un rostro muerto, como escuchar un labio ya cerrado. Mudos, descenderemos al abismo. (Cesare Pavese) $^{8}$

\section{REFERENCIAS}

1. Parada, E (Coord.). Psicología y Emergencia. Habilidades psicológicas en las profesiones de Socorro y Emergencia. Bilbao: Desclée de Brower; 2008.
2. Robles JI, Medina JL. Intervención psicológica en las catástrofes. Madrid: Síntesis; 2012.

3. Saramago J. Ensayo sobre la ceguera. Madrid: Ed Alfaguara; 2010.

4. Acinas P, Parada E, Muñoz FA. Gestión de emergencias con comportamiento violento (capítulo 10). En: Parada E, coordinador. Psicología y Emergencia. Habilidades psicológicas en las profesiones de Socorro y Emergencia. Bilbao: Desclée de Brower; 2008: 367-416.

5. Robles JI. Manual de Salud mental en Desastres. Madrid: Síntesis; 2010.

6. Josh Malerman J. A ciegas. Barcelona: Ed Planeta-Minotauro; 2015.

7. Acinas MP. Intervención psicológica en crisis suicidas (capítulo 11). En Ansean A (Dir.). Suicidios. Manual de prevención, intervención y postvención de la conducta suicida. Madrid: Fundación Salud Mental España; 2014: 269-304.

8. Pavese, C. Vendrá la muerte y tendrá tus ojos. Poesía moderna mexicana. 1950. El mejor poema del siglo XX. Wordpress [Internet]

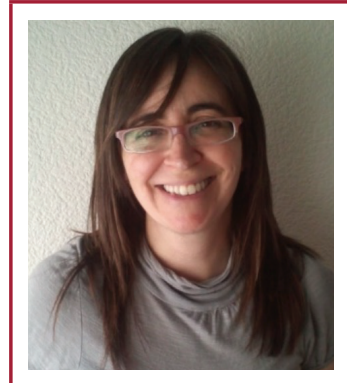

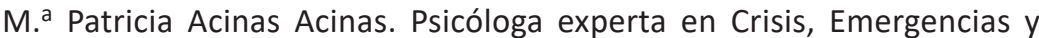
Catástrofes. Miembro Co-Fundadora y Secretaria de SEPADEM (Sociedad Española de Psicología Aplicada a Desastres, Urgencias y Emergencias). Lleva trabajando más de veinte años en el ámbito extrahospitalario y hospitalario en Servicios Médicos (incluyendo Cuidados Paliativos). Compagina actividad asistencial y docente en másters y cursos en varias universidades. Sus áreas de interés son: intervención en crisis (entre otras, en conducta suicida), trauma, duelo, (auto)cuidado de profesionales sanitarios y comunicación en entornos sanitarios. 